\author{
Beatriz Rueda ${ }^{1 \star}$ and Alemán JF ${ }^{2}$ \\ ${ }^{1}$ Department of Personality Psychology, Assessment \\ and Psychological Treatment, Faculty of Psychology \\ - UNED, C/ Juan del Rosal, 10, 28040 Madrid, \\ Spain \\ ${ }^{2}$ Agaete Health Center. Primary Care Service. \\ Canary Islands Health Service. C/ Agustín del Álamo \\ s/n, 35480 Las Palmas, Spain \\ Dates: Received: 01 September, 2015; Accepted: \\ 23 November, 2015; Published: 26 November, 2015 \\ *Corresponding author: Beatriz Rueda, Department \\ of Personality Psychology, Assessment and \\ Psychological Treatment, Faculty of Psychology - \\ UNED,C/ Juan del Rosal, 10, 28040 Madrid, Spain, \\ Tel: 0034913986281; Fax: $0034913986298 ;$ E-mail: \\ brueda@psi.uned.es \\ www.peertechz.com
}

Keywords: Anxiety; Depression; Alexithymia; Women; Hypertension

\section{Research Article \\ Anxiety and Depression in Hypertensive Women: Influence on Symptoms and Alexithymia}

\begin{abstract}
Objectives: Depression and anxiety are common mental disorders in women with cardiovascular disease. However, little research has examined the role of these disorders among women suffering from essential hypertension (EH). The present study explored the prevalence of both depression and anxiety in women with hypertension. It also examined the relationships of depression and anxiety with the frequency and severity of physical symptoms, alexithymia and the dimensions of difficulty in identifying and describing feelings (DIF and DDF).

Method: The sample consisted of 111 women (mean age $=58$ years) who attended a health care center to control their hypertension. Participants completed the Hospital Anxiety and Depression Scale (HADS), a checklist of physical symptoms and the Twenty-Item Toronto Alexithymia Scale (TAS-20).

Results: The prevalence of anxiety was higher (65\%) than the prevalence of depression (30\%). Bivariate correlations showed that depression and anxiety were associated with more frequent and greater levels of physical symptoms, and more alexithymia. In multiple regression analyses, only anxiety positively predicted the frequency and severity of the symptoms, and the dimensions of DIF and DDF. However, with respect to total alexithymia, both depression and anxiety emerged as positive and independent predictors.

Conclusions: The results highlight the importance of detecting anxiety disorders in women with $\mathrm{EH}$ due to their high prevalence. They also provide evidence of the independent role that both depressive and anxiety disorders can play when predicting alexithymia in these patients.
\end{abstract}

\section{Introduction}

Cardiovascular disease (CVD) is one of the leading causes of mortality and morbidity worldwide. One of the main risk factors that can accelerate the onset and development of CVD is essential hypertension [1]. Essential hypertension also constitutes a chronic health problem whose management entails adherence to pharmacological treatment and a change of the patient's unhealthy habits, which can worsen his or her physical and emotional wellbeing [2].

Regarding the etiology, prognosis and clinical manifestations of both CVD and essential hypertension, there is an increasing recognition of the remarkable influence that gender differences have on these diseases [3]. Up to 55 years of age CVD usually appears in men before it appears in women. However, the prevalence of both CVD and hypertension increases abruptly in women after menopause. Women with CVD present worse diagnoses and are less likely to be referred to therapeutic procedures and cardiac rehabilitation [4]. Moreover, women with CVD rapidly resume the tasks associated with their social and family roles because of their sense of responsibility, tend to have lower self-esteem and often exhibit an amplified perception of physical symptoms $[4,5]$.

Despite the relevance of these findings, it should be noted that substantially less research has focused on gender differences and psychosocial aspects concerning hypertension. Some studies have shown that hypertensive women perceive less control over their health and report greater physical symptoms and sleeping difficulties than men $[6,7]$.

Furthermore a great number of studies have suggested that depression and anxiety can contribute to CVD risk, either increasing the incidence of this pathology in healthy people [8], or worsening the prognosis in individuals with established CVD [9].

Depression has been found to be a strong predictor of recurrent CVD events and a worse adjustment to this illness [4,5]. Moreover, it has been estimated that the prevalence of depression in the population of patients with CVD varies between 20 and 35\% [10]. In hypertensive patients, depression has also been linked to a lower quality of life and well-being and worse adherence to pharmacological treatment [1113].

In the case of women who have either CVD or hypertension, these negative consequences are also evident. For example, it has been observed that depression in women who suffered from CVD is related to a worse physical and mental quality of life, a higher number of symptoms and more difficulties when performing everyday activities $[14,15]$. Hypertensive women also tend to report more emotional distress compared to hypertensive male patients $[7,16]$.

Regarding anxiety there is evidence supporting that between 15 and $20 \%$ of patients with CVD exhibit anxious symptoms and some type of anxiety disorder [17]. This percentage seems to increase in 
the case of essential hypertension. In this line, some investigations have revealed that anxiety could affect $57 \%$ of people who suffer from hypertension [18].

Anxiety has also been linked to a greater probability of death due to coronary disease [19], and is likely to increase the risk that healthy women will suffer from hypertension [20]. Some results have also shown that anxiety predicts, to a greater extent than depression, the occurrence of more coronary events [21], hospitalizations and doctor visits [22]

Despite this empirical support, until now, the role that anxiety can play in the population of women who suffer from hypertension has not been thoroughly examined. Equally, the understanding of the relative and negative impact that both depression and anxiety could have on hypertensive women's health has been rarely addressed.

The study by Hildingh \& Baigi [23], which was conducted with a sample of hypertensive patients which were not differentiated by gender, highlighted that anxiety symptoms were related to lower psychological well-being and more sleep problems. Similar results were shown in the study by Rueda \& Pérez-García [24], in which the emotional distress reported by hypertensive patients predicted worse physical and psychological well-being. In this study the variable of emotional distress was calculated by adding the scores of anxiety and depression, thus, it was not possible to compare the contribution of both disorders to the degree of well-being experienced by the patients.

Taking these results into account, it could be important for clinical and also psychotherapeutic purposes, first, to clearly identify and assess the prevalence of depressive and anxiety disorders in hypertensive women. And second, to determine the specific contribution that each of these two emotional disorders can make in the prediction of the perceived symptoms, which can be regarded as an indicator of poor physical and psychological health in these women.

On the other hand there is evidence showing that some patients with CVD could have alexithymia and, as a result, suffer from a deficit in their emotional processing $[25,26]$.

Alexithymia can be defined as a cognitive-affective characteristic that reflects a lack of ability to understand and describe emotions, a deteriorated ability to imagine and generate fantasies, and an externally oriented thinking $[27,28]$. Alexithymia has been widely measured by the Twenty-Item Toronto Alexithymia Scale (TAS-20) [29]. This scale consists of three subscales, difficulty in identifying feelings (DIF), difficulty in describe feelings (DDF) and an externally oriented thinking (EOT), which are theoretically consistent with the construct of alexithymia.

In a healthy population it has been found that when there is a moderate level of alexithymia (TAS-20>49), the risk of suffering from both hypertension and arteriosclerosis increases [30]. In hypertensive people, alexithymia has also been linked to increased severity of hypertension [31]. Equally, the research conducted by Alemán \& Rueda [16], highlighted that the patients who had hypertension for a long duration (> 5 years) presented a higher level of alexithymia compared to patients who suffered from hypertension for a shorter time $(<1$ year $)$.
Depression and anxiety have been demonstrated to be positively associated with global alexithymia and specially with the dimensions of DIF and DDF [32,33]. In contrast, the dimension of EOT seems to be much less relevant when considering its contribution to the presence of both depression and anxiety.

Some investigations have demonstrated that alexithymic patients who suffered from CVD [26], or another type of chronic pathology, such as asthma or psoriasis [34,35], scored significantly higher on both anxiety and depression. However, there is also evidence supporting the lack of association between alexithymia, depression and anxiety [30].

Overall, the investigation of the relationship between depression and anxiety with alexithymia and the facets of DIF and DDF in hypertensive women has received little attention. Recent research [16], has evidenced that emotional distress was positively correlated with alexithymia in hypertensive patients. Nonetheless, neither the specific predictive utility of both depression and anxiety with respect to alexithymia, nor the inclusion of the dimensions of DIF and DDF, were taken into account in this study when examining the female subgroup of the sample. Addressing this issue could be relevant from an empirical and clinical point of view, since it could provide more useful information about the manner and the extent to which depressive and anxiety disorders may be specifically and differentially related to alexithymia in women with essential hypertension.

In the present research, we first aimed to explore the prevalence of anxiety and depression in a sample of hypertensive women. Second, we tested how these two emotional disorders were related to physical symptoms, alexithymia and the dimensions of DIF and DDF. And third, we compared the independent contribution of both depression and anxiety in the prediction of physical symptoms, alexithymia and the dimensions of DIF and DDF.

We expected that both anxiety and depression would be significantly associated with physical symptoms, alexithymia and the dimensions of DIF and DDF. We also hypothesized that both disorders would positively predict the above-mentioned outcome variables.

\section{Methods \\ Participants and procedure}

To conduct this research, we used a target population of 463 women with a diagnosis of either moderate or chronic essential hypertension. These women were included in a program of periodic visits for the control of their hypertension. These visits occurred at a primary health care center of Gran Canaria, Spain. The study was approved by the health center's ethics committee.

The sample was selected through systematic random sampling. The inclusion criteria were as follows: aged between 18 and 70 years and having a diagnosis of essential hypertension. Exclusion criteria included the follow: having a diagnosis of established cardiovascular or cerebrovascular disease, suffering from another type of chronic illness, such as renal insufficiency, cancer, diabetes, asthma, or psychiatric illness, and/or having been in psychological treatment during the last year. 
Of the 463 hypertensive women who were potential participants, 170 were recruited to participate. Of these, thirty-five were eliminated for several reasons: twenty-one patients were not contacted, $14 \mathrm{did}$ not fulfill the inclusion criteria and $17 \mathrm{did}$ not provide the informed consent. Hence, 118 women agreed to participate in the investigation and were informed about the purpose of the study. Once they signed the informed consent, they were provided with the booklet with different scales to take home and to return completed to the primary health center.

Seven participants were dismissed from the study: four of them because they had not adequately completed the booklet and three because they were considered as outliers after an initial review of the collected data. Therefore, the final study sample was composed of 111 women with a mean age of 58 years $(S D=9.66)$.

\section{Measures}

The booklet included a series of questions regarding sociodemographic aspects and questions referring to hypertension. It also included the following scales:

The Hospital Anxiety and Depression Scale (HADS) [36]: This scale assesses the level of anxiety and depression resulting from having a health problem. The scale used in this investigation was based on the original version [36], and on previous studies $[37,38]$. The instrument contains 14 items divided into the subscales of anxiety (7 items) and depression (7 items). Each item is rated on a four-point scale ranging from 0 to 3 . Based on previous studies [39], a score $\geq 8$ on each subscale was considered as an indicator of the presence of either depression or anxiety. The Cronbach's alpha reliability coefficients of both subscales were 0.69 in the present study.

A Checklist of Physical Symptoms: This self-report questionnaire was designed to assess the number and severity of a list of physical symptoms (i.e., headache, dizziness, nervousness, palpitations and respiratory difficulty). The patients had to select the number of symptoms they experienced in that moment and also indicate their severity on a five-point scale (from 1="Nothing or almost nothing" to $5=$ "Very much"). Cronbach's alpha reliability coefficients were .61 for the frequency subscale and .73 for the severity subscale.

The Toronto Alexithymia Scale 20 (TAS-20) [29]: This questionnaire measures the level of alexithymia. The items used in this questionnaire were derived from previous studies [40], and a pilot study [38]. The instrument is composed of 20 items rated on a five-point scale (from 1="Nothing" to $5=$ "A lot"). The scale consists of three subscales: the TAS 1, which measures the difficulty in identifying feelings (DIF); the TAS 2, which evaluates the difficulty in describing feelings (DDF); and the TAS 3 , which measures utilitarian and externally oriented thought (EOT). In this study, we used the scores yielded on the total scale and on the TAS 1 and TAS 2 subscales respectively. The EOT subscale was not utilized since this dimension does not seem particularly relevant in patients with either CVD or hypertension.

The Cronbach's alpha reliability coefficients were appropriate (0.82 for the total TAS-20, 0.85 for the TAS- 1 and 0.78 for the TAS- 2 ).

\section{Statistical analysis}

First, three multivariate outliers with extreme scores on two variables of the study were found and subsequently eliminated. Assumptions of normality, linearity and homoscedasticity were also checked and met for the aforementioned variables. Second, to calculate the prevalence of anxiety and depression in the sample, two groups were formed using a score of $\geq 8$ as the cut-off point on the subscales of depression and anxiety. Then, the frequency and percentage of women belonging to each of these groups were obtained.

To examine the relationship of depression and anxiety with the frequency and severity of the physical symptoms, alexithymia and the dimensions of DIF and DDF, Pearson correlation coefficients were calculated. Finally, after checking that there were no effects of multicollinearity between anxiety and depression, several multivariate regression analyses were conducted. Anxiety and depression were introduced as the predictor variables, and frequency and severity of the physical symptoms, alexithymia and the facets of DIF and DDF entered as the outcome variables respectively. Statistical analyses were performed with SPSS version 20.0. In all of the analyses, the level of significance used was $<0.05$.

\section{Results}

\section{Descriptive and correlational analyses}

A summary of the socio-demographic and clinical characteristics of the sample is presented in Table 1. Of the 111 women who composed the sample, $69 \%$ were married, and the rest $(31 \%)$ were single, divorced, or widowed. With respect to the duration of hypertension, $12 \%$ suffered from hypertension for less than one year, $40 \%$ had hypertension for a period of 1-5 years, and the remaining $48 \%$ had hypertension for more than five years. Furthermore, the majority of the sample (96\%) reported adequately complying with the prescribed treatment. Seventy percent of the women indicated properly complying with the diet, whereas $30 \%$ did not. Regarding exercise, $89 \%$ of the women reported that they exercised regularly, whereas $11 \%$ revealed not exercising regularly.

\begin{tabular}{|l|c|c|}
\hline \multicolumn{3}{|l|}{ Table 1: Demographic and clinical characteristics of the sample. } \\
\hline & N & $\%$ \\
\hline Marital Status & 77 & 69 \\
Married & 34 & 31 \\
\hline Single, divorced or widowed & & \\
\hline Hypertension duration & 13 & 12 \\
<1year & 45 & 40 \\
1 to 5 years & 53 & 48 \\
> 5 years & & \\
Adherence to antihypertensive medication regimen & 107 & 96 \\
Yes & 4 & 4 \\
No & & \\
Diet compliance & 78 & 70 \\
Yes & 33 & 30 \\
No & & \\
Regular exercise & 99 & 89 \\
Yes & 12 & 11 \\
No & & \\
\hline Age & Mean & DT \\
\hline & 58 & 9.66 \\
\hline
\end{tabular}


Means values, standard deviations and the ranges of the scores yielded on the psychosocial variables included in the study are shown in Table 2.

As can be observed in Table 3, correlational analyses showed that anxiety and depression were positively associated with the frequency and severity of physical symptoms, and with alexithymia and the dimensions of DIF and DDF. All the correlations with anxiety were higher than those observed in relation to depression.

\section{Prevalence of depression and anxiety}

The prevalence of depression and anxiety is shown in Table 4. Following the specified cut-off points for the depression subscale, depression was observed in $30 \%$ of the sample (score of $\geq 8$ ), whereas this disorder was not confirmed to be present in the remaining $70 \%$ of the sample (score of $\leq 8$ ). These data significantly varied concerning the prevalence of anxiety. Sixty-five percent of the women showed having an anxiety disorder (score of $\geq 8$ ), whereas there was not any evidence of this type of disorder in the remaining $35 \%$ (score of $\leq 8$ ).

Prediction of symptoms, alexithymia and DIF and DDF

Finally, different regression analyses were performed to determine the predictive and independent capacity of anxiety and depression with respect to the frequency and severity of the physical symptoms, alexithymia and the facets of DIF and DDF. Table 5 shows the results of these analyses.

Regarding the frequency of the symptoms, the percentage of the total variance explained by the model was $3 \%$, whereas in relation to the severity of the symptoms, the model accounted for $2 \%$ of the total variance. In both cases, anxiety emerged as a significant predictor. Depression did not significantly predict any of these outcomes.

Considering alexithymia, both anxiety and depression significantly and positively predicted this outcome accounting for $7 \%$ of the total variance in the regression model. In contrast, with regard to the dimensions of DIF and DDF, anxiety was the only significant predictor of both outcomes since depression did not make any significant contribution. In relation to DIF the model accounted for $6 \%$ of the total variance and respecting DDF the model explained $2 \%$ of the total variance.

\section{Discussion}

In this study we aimed at determining the prevalence of depression and anxiety in a sample of hypertensive women. We also tested the possible relationship of these two disorders with the frequency and severity of physical symptoms, alexithymia and the dimensions of DIF and DDF.

According to the results, $30 \%$ of the sample reported suffering from depression. This percentage is within the range indicated by other investigations that have shown that between 20 and $45 \%$ of the total population presenting CVD tend to experience some type of depressive symptoms or depressive disorder [41].

In contrast, the percentage of women who reported suffering from anxiety was notably higher than that observed in the case of depression. Specifically, $65 \%$ of the women included in the sample reported having anxiety. This finding supports previous studies [18], although some investigations have indicated that the prevalence of anxiety disorders in people diagnosed with CVD could be lower, ranging between 15 and 20\% [17]. Taking into account the greater

\begin{tabular}{|l|r|}
\hline Table 2: Descriptive statistics of the study variables. & \multicolumn{2}{|c|}{ M (DT) } \\
\hline Depression & $6.28(3.63)$ \\
\hline Anxiety & $0.52(3.67)$ \\
\hline Frequency of Physical Symptoms & $0-20$ \\
\hline Severity of Physical Symptoms & $2.18(1.30)$ \\
\hline Alexithymia & $8.36(3.08)$ \\
\hline $\begin{array}{l}\text { Difficulty Identifying Feelings (DIF) } \\
\text { Difficulty Describing Feeling (DDF) }\end{array}$ & $52.88(12.16)$ \\
\hline
\end{tabular}

Table 3: Intercorrelations among variables.

\begin{tabular}{|c|c|c|c|c|c|c|c|}
\hline & 1 & 2 & 3 & 4 & 5 & 6 & 7 \\
\hline 1. Depression & --- & & & & & & \\
\hline 2. Anxiety & $0.56^{\star * \star}$ & -- & & & & & \\
\hline 3. Frequency Physical Symptoms & $0.33^{\star \star *}$ & $0.40^{* \star *}$ & --- & & & & \\
\hline 4. Severity Physical Symptoms & $0.29 * \star$ & $0.36^{\star \star \star}$ & $0.80^{\star \star \star \star}$ & --- & & & \\
\hline 5. Alexithymia & $0.42^{\star \star \star}$ & $0.47^{\star \star \star *}$ & $0.40^{\star \star \star \star}$ & $0.37^{\star \star \star \star}$ & -- & & \\
\hline 6. DIF & $.34^{\star \star * *}$ & $.40^{\star \star \star *}$ & $.48^{\star * *}$ & $.51^{\star \star \star}$ & $.81^{\star \star \star}$ & --- & \\
\hline 7. DDF & $.29^{*}$ & $.36^{\star \star \star}$ & $.34^{\star * *}$ & $.21^{*}$ & $.68^{\star \star \star}$ & $.48^{\star * \star}$ & -- \\
\hline
\end{tabular}


Table 4: Depression and anxiety disorder prevalence.

\begin{tabular}{|l|r|}
\hline Table 4: Depression and anxiety disorder prevalence. & \\
\hline & \\
\hline Depression Disorder & \\
Yes (score $\geq 8)$ & $33(30 \%)$ \\
No (score $<8)$ & $78(70 \%)$ \\
\hline Anxiety Disorder & \\
Yes (score $\geq 8)$ & \\
No (score $<8)$ & \\
\hline
\end{tabular}

Table 5: Regression analysis predicting frequency and severity of physical symptoms, alexithymia and the dimensions of DIF and DDF.

\begin{tabular}{|c|c|c|c|c|c|}
\hline & $R 2$ & $F$ & $g l$ & $t$ & $\beta$ \\
\hline $\begin{array}{l}\text { Frequency of Physical Symptoms } \\
\text { Depression } \\
\text { Anxiety }\end{array}$ & 0.17 & $11.43^{\star \star \star}$ & 2,110 & $\begin{array}{l}0.15 \\
0.31\end{array}$ & $\begin{array}{c}0.15 \\
2.99 * *\end{array}$ \\
\hline $\begin{array}{l}\text { Severity of Physical } \\
\text { Symptoms } \\
\text { Depression } \\
\text { Anxiety }\end{array}$ & 0.14 & $9.05^{\star \star \star}$ & 2,110 & $\begin{array}{l}0.13 \\
0.29\end{array}$ & $\begin{array}{c}0.24 \\
2.37^{\star * \star}\end{array}$ \\
\hline $\begin{array}{l}\text { Alexithymia } \\
\text { Depression } \\
\text { Anxiety }\end{array}$ & 0.26 & $18.62^{\star \star *}$ & 2,110 & $\begin{array}{c}2.33^{\star} \\
3.37^{\star \star}\end{array}$ & $\begin{array}{l}0.23 \\
0.34\end{array}$ \\
\hline $\begin{array}{l}\text { DIF } \\
\text { Depression } \\
\text { Anxiety }\end{array}$ & 0.25 & $17.91^{\text {*** }}$ & 2,110 & $\begin{array}{c}.98 \\
4.35^{\star \star \star}\end{array}$ & $\begin{array}{c}0.9 \\
0.44\end{array}$ \\
\hline $\begin{array}{l}\text { DDF } \\
\text { Depression } \\
\text { Anxiety }\end{array}$ & 0.15 & $9.35^{\star \star \star}$ & 2,110 & $\begin{array}{c}1.49 \\
2.63^{\star}\end{array}$ & $\begin{array}{l}0.16 \\
0.27\end{array}$ \\
\hline
\end{tabular}

prevalence of anxiety in our sample, one could speculate that the detection and diagnosis of anxiety disorders may have been incorrectly made. In this line, it has been suggested that the anxiety symptoms reported by hypertensive patients can be erroneously normalized in the health care settings [17], or be confused with other symptoms specifically associated with hypertension or with the prescribed antihypertensive medication.

The results of the present study also showed that depression and anxiety positively correlated with the frequency and severity of physical symptoms. Nonetheless, and contrary to our hypothesis, when anxiety and depression jointly entered into the regression analysis, only anxiety emerged as the significant predictor of increased frequency and severity of symptoms.

This result may be, at least, attributable to the very nature of the symptoms assessed in the study. These symptoms may have more to do with autonomic arousal (i.e., "palpitations", "nervousness", "dizziness" or "respiratory difficulty") than with other more somatic indicators, such as fatigue, anhedonia or lack of energy, which would be more typical in patients with both a depressive disorder and CVD [42]. Thus, the kind of symptoms included in the investigation would be more consistently linked to the existence of an anxiety disorder, which, in turn, could contribute to perceive the symptoms in a more amplified and threatening way [43].

Although previous research $[7,11,13,16,23]$, has confirmed the negative association of depression and anxiety with the level of wellbeing experienced by hypertensive patients, most of these studies have only examined the presence of one of the two disorders or have considered a global measure of distress. Considering this empirical point, the findings of the present study are relevant for two reasons. First, because they allow expand previous evidence by comparing the relative contribution of both depression and anxiety in women having hypertension. And second, because they help to clarify the predictive weight of both disorders in relation to some indicators of reduced well-being, such as the frequency and severity of the physical symptoms.

On the other hand, as expected, we found that both depression and anxiety were positively related to alexithymia and the domains of DIF and DDF, and were also independent and positive predictors of alexithymia. All these results are in agreement with other studies confirming the positive relationship of depression and anxiety with alexithymia in patients with CVD $[26,44]$.

However the results obtained in this study are particularly noteworthy because they provide evidence of the type of relationships among these variables in a sample of hypertensive women and because, overall, research on these psychosocial aspects in hypertensive women is still scarce.

These results also suggest that since the presence of depression or anxiety implies greater psychological vulnerability and a constellation of cognitive, emotional, behavioral and somatic symptoms, hypertensive women who suffered from one of these disorders could also have an impaired ability to identify, process or express a different range of emotions [45], thus showing a higher level of alexithymia. Alternatively, it could be argued that in women suffering from essential hypertension, depression and anxiety may be associated 
with alexithymia to the extent that alexithymia may be acting as a form of maladaptive response [26,46]. This inappropriate response could function as a way to cope with the stressful event of suffering from hypertension and its possible negative and severe consequences.

Contrary to our hypothesis and previous studies [32,33], regression analysis showed that the domains of DIF and DDF were only predicted by anxiety since depression did not emerge as a significant predictor of these outcomes. In line with these results one could speculate that women from our study, who also suffered from anxiety, could experience an exaggerated physiological reactivity. This increased physiological response might hinder the ability to identify and distinguish feelings from physical reactions, which could, in turn, lead to experience and report more frequent and severe symptoms. Although this explanation is, however, tentative and requires more empirical evidence to be tested, some investigations have supported the connection between alexithymia and elevations in sympathetic arousal [47].

The present research has a number of limitations that should be noted. First, the variables used in the study were all self-reported. Relying on these self-rated measures can have biased the participants responses and overestimated the degree of overlap between the variables, particularly the size of the associations between anxiety and the frequency and severity of the symptoms. In addition, it would have been interesting to examine the possible degree of overlap between depression and anxiety in the sample, taking into account that both disorders tend to be strongly related.

Second, some factors, such as comorbid medical conditions and the side effects of prescribed pharmacological treatment, could have negatively affected the prevalence of depression and anxiety, the frequency and severity of the symptoms reported by the hypertensive women and maybe their level of alexithymia and the dimensions of DIF and DDF. Since these variables were not controlled in the investigation, future studies should explore whether the prevalence of depressive and anxiety disorders, and their associations with the symptoms and alexithymia, could change depending of the level of comorbidity and the negative effects due to the pharmacological treatment

Finally, the cross-sectional nature of this research prevents the establishment of causal relationships between the different variables and the examination of reciprocal effects over time. For example, alexithymia could be also considered as a predictor of depressive and anxiety disorders, and the presence of more symptoms could increase the severity of these mental disorders. Hence, longitudinal studies in which longer time intervals are established should be conducted to clarify these possible reciprocal relations.

\section{Conclusions}

Despite these limitations, our study provides more insight on important issues that remained underexplored in the field of gender differences and hypertension. First, it reports the prevalence of depression and anxiety in women with essential hypertension. Second, it sheds more light on the relevant role that anxiety has in predicting more frequent and severe symptoms, and more difficulty in identifying and describing the feelings. And finally, it illustrates how both depression and anxiety are independently associated with alexithymia in women with essential hypertension.

\section{References}

1. Mancia G, Fagard R, Narkiewicz K, Redón J, Zanchetti A, et al. (2013) 2013 ESH/ESC Guidelines for the management of arterial hypertension: the Task Force for the management of arterial hypertension of the European Society of Hypertension (ESH) and of the European Society of Cardiology (ESC). J Hypertens 31: 1281-1357.

2. Pérez-García AM, Sanjuán P, Rueda B (2014) Psychological aspects of hypertension [Aspectos psicológicos de la hipertensión]. Madrid: Síntesis.

3. Fodor JG, Tzerovska R (2004) Coronary heart disease: Is gender important? Journal of men's health and gender 1: 32-37.

4. Abbey SE, Stewart DE (2000) Gender and psychosomatic aspects of ischemic heart disease. J Psychosom Res 48: 417-423.

5. Low CA, Thurston RC, Matthews KA (2010) Psychosocial factors in the development of heart disease in women: Current research and future directions. Psychosom Med 72: 842-854.

6. Robbins MA, Elias MF, Croog SH, Colton T (1994) Unmedicated blood pressure levels and quality of life in elderly hypertensive women. Psychosom Med 56: 251-259.

7. Rueda B, Pérez García A.M (2006) Gender and social support in the context of cardiovascular disease. Women \& Health 43: 59-73.

8. Bacon SL, Campbell TS, Arsenault A, Lavoie KL (2014) The Impact of Mood and Anxiety Disorders on Incident Hypertension at One Year. Int J Hypertens.

9. Huffman JC, Celano CM, Beach SR, Motiwala SR, Januzzi JL (2013) Depression and cardiac disease: Epidemiology, mechanisms, and diagnosis. Cardiovasc Psychiatry Neurol.

10. Rumsfeld JS, Michael H (2005) Depression and cardiovascular disease: A call for recognition. Circulation 11: 250-253.

11. Bosworth HB, Bartash RM, Olsen MK, Steffens DC (2003) The association of psychological factors and depression with hypertension among older adults. Int J Geriatr Psychiatry, 18: 1142-1148.

12. Rueda B, Pérez-García AM (2006 $)$ A prospective study of the effects of psychological resources and depression in essential hypertension. J Health Psychol, 11: 129-140.

13. Wang PS, Bohn RL, Knight E, Glynn RJ, Mogun H, et al. (2002). Noncompliance with antihypertensive medications: The impact of depressive symptoms and psychosocial factors. Journal of General Internal Medicine, 17: $504-511$.

14. Emery CF, Frid DJ, Engebretson TO, Alonzo AA, Fish A, et al. (2004) Gender differences in quality of life among cardiac patients. Psychosom Med 66: 190197.

15. Rutledge T, Reis SE, Olson M, Owens J, Kelsey SF et al. (2006) Depression is associated with cardiac symptoms, mortality risk, and hospitalization among women with suspected coronary disease: The NHLBI-Sponsored WISE study. Psychosom Med 68: 217-223.

16. Alemán JF, Rueda B (2014) Factors associated with emotional vulnerability and low adherence to treatment in essential hypertension [Factores asociados con la vulnerabilidad emocional y la baja adherencia al tratamiento en la hipertensión esencial]. Boletín de Psicología 112: 35-52.

17. Tully, PJ, Cosh SM, Baumeister H (2014) The anxious heart in whose mindo? A systematic review and meta-regression of factors associated with anxiety diagnosis, treatment and morbidity risk in coronary heart disease. $\mathrm{J}$ Psychosom Res 77: 439-448.

18. Kretchy IA, Owusu Daaku FT, Danquah SA (2014) Mental health in hypertension: Assessing symptoms of anxiety, depression and stress on antihypertensive medication adherence. Int J Ment Health Syst doi:10.1186/17524458-8-25. 
19. Kawachi I, Sparrow D, Vokonas PS, Weiss ST (1994) Symptoms of anxiety and risk of coronary heart disease: The Normative Aging Study. Circulation 90: $2225-2229$

20. Räikkönen K, Matthews KA, Kuller LH (2001) Trajectory of psychological risk and incident hypertension in middle-aged women. Hypertension 38: 798-802.

21. Vogelzangs $N$, Seldenrijk $A$, Beekman $A$, van Hout $H$, de Jonge $P$, et al. (2010) Cardiovascular disease in persons with depressive and anxiety disorders. J Affect Disord 125: 241-248.

22. Strik J, Denollet J, Lousberg R, Honig A (2003) Comparing symptoms of depression and anxiety as predictors of cardiac events and increased health care consumption after myocardial infarction. J Am Coll Cardiol, 42: 18011807.

23. Hildingh C, Baigi A (2010) The association among hypertension and reduced psychological well-being, anxiety and sleep disturbances: A population study. Scand J Caring Sci, 24: 366-371.

24. Rueda, B., \& Pérez-García, A.M. (2004). Influence of negative emotions on perceived health competence and quality of life in essential hypertension [Influencia de las emociones negativas sobre la percepción de competencia en salud y la calidad de vida en la hipertensión esencial]. Análisis y Modificación de Conducta, 30, 841-863.

25. Koh KB, Cho SY, Kim JW, Rho KS, Lee SH, et al. (2004) The Relationship of Anger Expression and Alexithymia with Coronary Artery Stenosis in Patients with Coronary Artery Diseases. Yonsei Med J 45: 181-186.

26. Kojima M, Frasure Smith N, Lespérance F (2001) Alexithymia following myocardial infarction psychometric properties and correlates of the Toronto Alexithymia Scale. J Psychosom Res, 51: 487-495.

27. Sifneos PE (1973) The prevalence of "alexythimic" characteristics in psychosomatic patients. Psychother Psychosom 22: 255-262.

28. Taylor GJ, Bagby RM, Parker JDA (1997) Disorders of affect regulation Alexithymia in medical and psychiatric illness. Cambridge: Cambridge University Press.

29. Bagby M, Parker DA, Taylor J (1994)The twenty-item Toronto Alexithymia Scale: I. Item selection and cross-validation of the factor structure. J Psychosom Res 38: 23-32.

30. Grabe HJ, Schwahn C, Barnow S, Spitzer C, John U, et al. (2010) Alexithymia hypertension, and subclinical atherosclerosis in the general population. $J$ Psychosom Res 68: 139-147.

31. Cage BC, Egan KJ (1984) The effect of alexithymia on morbidity in hypertensives. Psychother Psychosom 41: 136-144.

32. Hendryx MS, Haviland MG, Shaw DG (1991) Dimensions of alexithymia and their relationships to anxiety and depression. J Pers Assess 56: 227-237.

33. Marchesi C, Brusamonti E, Maggini C (2000) Are alexithymia, depression, and anxiety distinct constructs in affective disorders? J Psychosom Res 49 43-49.

34. Korkoliakou P, Christodoulou C, Kouris A, Porichi E, Efstahiou V, et al. (2014)
Alexithymia, anxiety and depression in patients with psoriasis: A case-control study. Ann Gen Psychiatry.

35. Tselebis A, Kosmas E, Bratis D, Moussas G, Karkanias A, et al. (2010) Prevalence of alexithymia and its association with anxiety and depression in a sample of Greek chronic obstructive pulmonary disease (COPD) outpatients. Ann Gen Psychiatry.

36. Zigmond AS, Snaith RP (1983) The Hospital Anxiety and Depression Scale. Acta Psychiatr Scand 67: 361-370

37. Martin CR, Thompson DR (2003) A psychometric evaluation of the hospital anxiety and depression scale in coronary care patients following acute myocardial infarction. Psychiatry Res 5: 193-201.

38. Rueda, B. (2004). Perceived competence and health: General approach and application to cardiovascular disease [Competencia percibida y salud: Aproximación general y aplicación a la enfermedad cardiovascular]. Unpublished doctoral dissertation. National Distance Education University, Madrid, Spain.

39. Roberts SB, Bonnici DM, Mackinnon AJ, Worcester MC (2001) Psychometric evaluation of the Hospital Anxiety and Depression Scale (HADS) among female cardiac patients. Br J Health Psychol 6: 373-383.

40. Martínez-Sánchez F (1996) Spanish adaptation of the Toronto Alexithymia Scale [Adaptación española de la Escala Toronto de Alexitimia]. Clínica y Salud, 7: 19-32.

41. Stafford L, Hons MA, Berk M, Jackson HJ (2007) Validity of the Hospital Anxiety and Depression Scale and Patient Health Questionnaire to screen for depression in patients with coronary artery disease. Gen Hosp Psychiatry 29 417-424.

42. Doyle F, Conroy R, McGee H (2007) Challenges in reducing depressionrelated mortality in cardiac populations: cognition, emotion, fatigue or personality? Health Psychology Review 1: 137-172.

43. Clark DA, Beck AT (2011) Cognitive therapy of anxiety disorders: Science and Practice. New York: The Guilford Press 1-310

44. Peters RM, Lumley MA (2007) Relationship of alexithymia to cardiovascular disease risk factors among African Americans. Comprehensive Psychiatry 48: 34-41.

45. van der Veek SMC, Nobel RA, Derks HHF (2012) The relationship between emotion awareness and somatic complaints in children and adolescents: Investigating the mediating role of anxiety and depression. Psychology \& Health 27: 1359-1374.

46. Lumley MA, Neely LC, Burger AJ (2007) The assessment of alexithymia in medical settings: Implications for understanding and treating health problems. J Pers Assess 89: 230-246.

47. Martínez Sánchez F, Ato M (2011) Sympathetic reactivity to experimentally induced stress in alexithymia. Anales de Psicología 27: 757-762.

48. Bunevicius A, Staniute M, Brozaitiene J, Pop V, Neverauskas J, Bunevicius $R$ (2013) Screening for anxiety disorders in patients with coronary artery disease. Health and Quality of Life Outcomes 11: 37

Copyright: (c) 2015 Rueda B, et al. This is an open-access article distributed under the terms of the Creative Commons Attribution License, which permits unrestricted use, distribution, and reproduction in any medium, provided the original author and source are credited. 